\title{
Registros de desastres associados à estiagem e seca na região do Alto Sertão da Paraíba
}

Registries of disasters associated to dry and drought in the region of Alto Sertão da Paraíba

\author{
SILVA $^{1}$, D. A. M.; MOURA ${ }^{2}$, O. M.; \\ diegoalangeo@gmail.com
}

\begin{abstract}
Resumo
Os desastres naturais de ordem climática é um problema histórico na região do semiárido nordestino. A Paraíba é um dos estados brasileiros que mais reconhece desastres de estiagem e seca. Diante desse cenário, buscou-se investigar a frequência dessas ocorrências em uma das regiões de clima semiárido da Paraíba. O objetivo desse artigo é analisar a distribuição espaço-temporal dos desastres deflagrados por estiagem e seca, os quais almejaram decretos por Situação de Emergência (SE) e por Estado de Calamidade Pública (ECP), entre os anos de 2003 a 2016, na região o Alto Sertão da Paraíba. Os dados de reconhecimentos dos desastres foram adquiridos na página do site do Sistema Nacional de Proteção e Defesa Civil (SINPDEC) do Ministério da Integração (MI). Foi contabilizado um total de 503 desastres climáticos na região. Desse montante, 493 foram desastres decretados por SE (485 por estiagem e 8 por seca) e 10 desastres de estiagem decretados por ECP.
\end{abstract}

Palavras-chave: Semiárido paraibano. Desastres Naturais. Decretos de Reconhecimento.

\begin{abstract}
The natural disasters of climatic order are a historical problem in the Northeast (Nordeste) semiarid region. Paraíba is one of the Brazilian states that most recognizes dry and drought disasters. Front of this scenario, we sought to investigate the frequency of this occurrences in one of the semi-arid climate regions of Paraíba. The objective of this article is to analyze the spatial and temporal distribution of the disasters caused by drought, which aimed at decrees by Emergency Situation (ES) and by State of Public Calamity (SPC), between the years of 2003 and 2016, in the region of Alto Sertão da Paraíba. The data of these disasters were found in the site of National System of Civil Protection of Ministry of Integration (MI). A total of 503 climatic disasters were recorded in the region. Of this amount, 493 were disasters decreed by ES (485 by dry and 8 by drought) and 10 disasters of drought decreed by SPC.
\end{abstract}

Keywords: Paraibano semi-arid. Natural Disasters. Recognition decrees

\section{INTRODUÇÃO}

Historicamente, o semiárido do Nordeste brasileiro sempre sofreu com o fenômeno da seca e da estiagem, o que consequentemente gerou muitos problemas socioambientais para a população. $\mathrm{O}$ desastre envolve extensivas perdas e danos humanos, materiais, econômicos ou ambientais, que excedem a capacidade da sociedade de lidar com o problema usando meios próprios (UNISDR, 2009, p. 9).

Conforme a atual Classificação e Codificação Brasileira de Desastres Naturais - COBRADE (BRASIL, 2012) os desastres climáticos são fenômenos naturais e estão associados a estiagem e a seca, além da baixa umidade do ar. A estiagem é definida como um período prolongado de baixa ou nenhuma pluviosidade, em que a perda de umidade do solo é superior à sua reposição, já a seca é 
definida como uma estiagem prolongada, durante um período de tempo suficientemente longo para que a falta de precipitação provoque grave desequilíbrio hidrológico. Segundo Tsakiris e Vangelis (2004), a seca não deve ser confundida com aridez, pois esta última é uma característica permanente do clima, resultante dos baixos níveis pluviométricos.

Segundo Moura et al (2017) a Paraíba é um dos estados que mais reconheceu desastres climáticos (estiagem e seca) em todo o território nacional entre os anos de 2003 a 2015. Essa informação torna-se um problema para a região do sertão paraibano tendo em vista que a agricultura e a pecuária são a base da economia local (MOREIRA, 2010).

A área de estudo da pesquisa, a microrregião pluviométrica do Alto Sertão da Paraíba, localiza-se na porção mais ao oeste do Estado e foi delimitada segundo critérios de distribuição espaço-temporal da precipitação proposto por Silva (2007). Cabe salientar que não é uma divisão política-administrativa. Além do Alto Sertão, Silva (2007) dividiu a Paraíba em outras cinco microrregiões pluviométricas: Litoral, Brejo, Agreste, Cariri/Curimataú e Sertão, conforme mostra a Figura 01.

\section{Microrregiões Pluviometricamente Homogêneas do Estado da Paraíba}

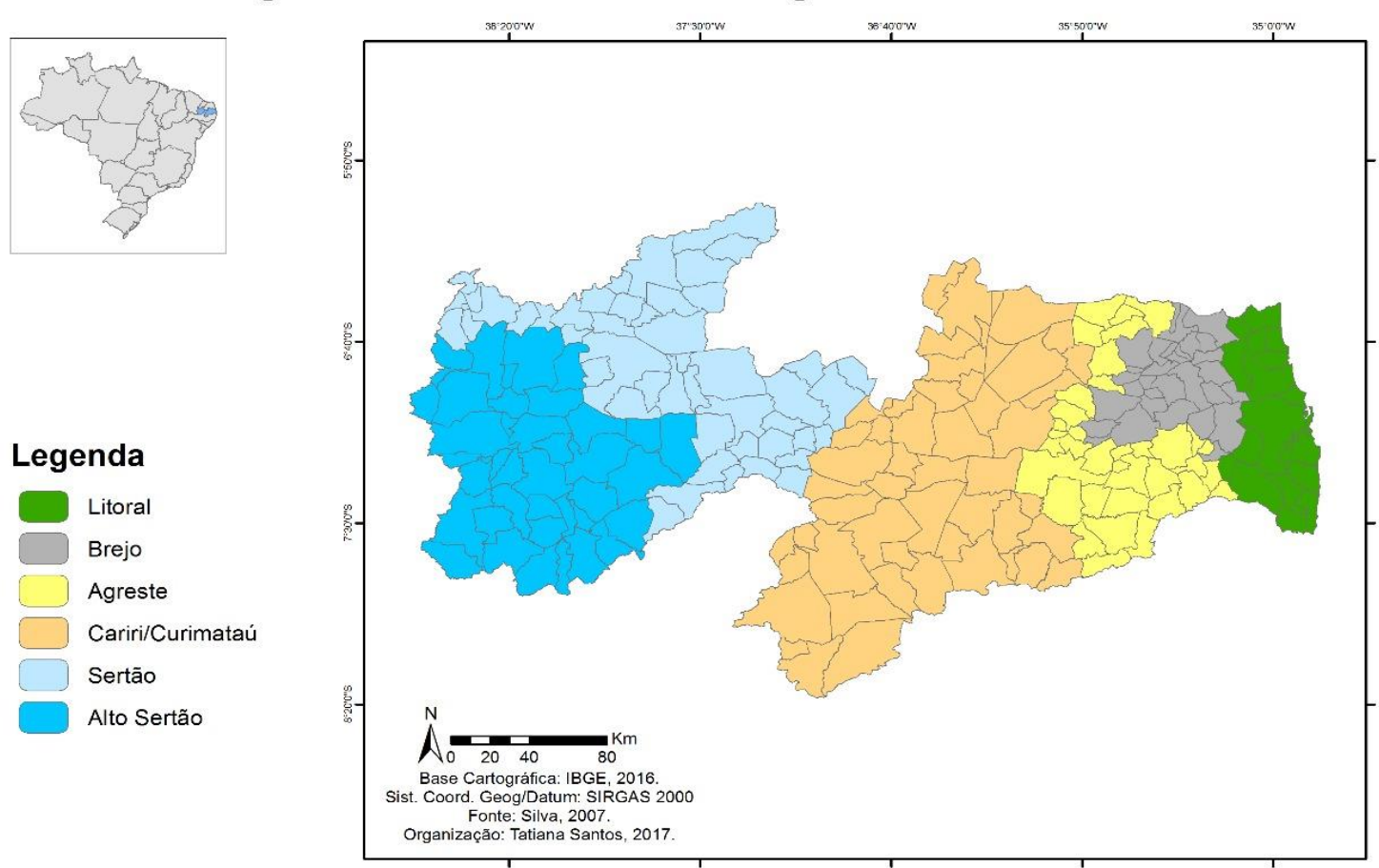

Figura 01: Distribuição espacial das microrregiões pluviométricas da Paraíba. Fonte: Silva, 2007.

Segundo Silva (2007), a média de chuvas na região pluviométrica do Alto Sertão é de aproximadamente $800,0 \mathrm{~mm} / \mathrm{ano}$, a qual ocorre de forma irregular durante todo o ano. Nessa região registram-se temperaturas com média anual de $27^{\circ} \mathrm{C}$ (AESA, 2017). A área do Alto Sertão apresenta uma vegetação xerófita com raízes pouco profundas que pode ser relacionada ao seu terreno que se caracteriza como pedregoso e muito raso o que dificulta a infiltração e armazenamento d'água (EMPRABA, 2009). 
A estação chuvosa na região ocorre entre os meses de fevereiro a maio e tem forte influência da Zona de convergência Intertropical - ZCIT que é o sistema atmosférico mais atuante no período chuvoso na região semiárida do Brasil. A ocorrência de estiagem e seca no Nordeste brasileiro pode estar associada a fenômenos como o El Niño e o Dipolo do Atlântico (aquecimento/esfriamento do Atlântico Norte/Sul), conforme já demonstrado pelos trabalhos desenvolvidos por Alves (1997) e Ferreira e Melo (2005).

Os estudos sobre os desastres deflagrados por estiagem e seca no estado da Paraíba são relevantes pelo fato de $80 \%$ de seu território estar inserido no domínio climático do Semiárido (AZEVEDO e SILVA, 1994). E mesmo sendo recorrentes os fenômenos de estiagem e de seca, existem poucos trabalhos que abordam a temática de desastres no sertão paraibano. Diante do exposto, propõe-se nessa pesquisa analisar a distribuição espaço-temporal dos reconhecimentos de Situação de Emergência (SE) e de Estado de Calamidade Pública (ECP) de natureza climática (seca e estiagem) na microrregião pluviometricamente homogênea do Alto Sertão no período de 2003 a 2016.

\section{METODOLOGIA}

As informações sobre as ocorrências de desastres climáticos que ensejaram decretos de Situação de Emergência e de Estado de Calamidade Pública foram adquiridos no site do Ministério da Integração Nacional, na página da Secretária Nacional de Proteção e Defesa Civil, entre o período de 2003 a 2016.

Os desastres de nível I ensejam a decretação de Situação de Emergência, enquanto os desastres de nível II a Estado de Calamidade Pública. Assim, os desastres podem ser classificados em dois de níveis de intensidade, a saber: Desastre de nível I - são aqueles em que os danos e prejuízos são suportáveis e superáveis pelos governos locais e a situação de normalidade pode ser restabelecida com os recursos mobilizados em nível local ou complementados com o aporte de recursos estaduais e federais, e Desastres de Nível II - são aqueles em que os danos e prejuízos não são superáveis e suportáveis pelos governos locais, mesmo quando bem preparados, e o restabelecimento da situação de normalidade depende da mobilização e da ação coordenada das três esferas de atuação do Sistema Nacional de Proteção e Defesa Civil - SINPDEC e, em alguns casos, de ajuda internacional (BRASIL, 2012)

Os dados foram organizados em planilhas eletrônicas do Microsoft Excel 2010 para a sistematização dos tipos de desastres (estiagem e seca), por ano e por municípios que integram a microrregião pluviometricamente homogênea do Alto Sertão a fim de contabilizar o número de ocorrências e estabelecer a frequência dos desastres. Posteriormente, os dados foram agrupados e 
representados através de gráficos e mapas temáticos. Os mapas foram elaborados no software QGis, versão 2.18.3.

\section{RESULTADOS E DISCUSSÃO}

A área de estudo (Figura 02) é composta por 39 municípios. A população total da área é de 456.741 habitantes segundo as estimativas demográficas do IBGE (2016), sendo o município de Sousa o mais populoso, com 69.196 habitantes, seguido por Cajazeiras (61.816 habitantes) e Itaporanga (24.674 habitantes).

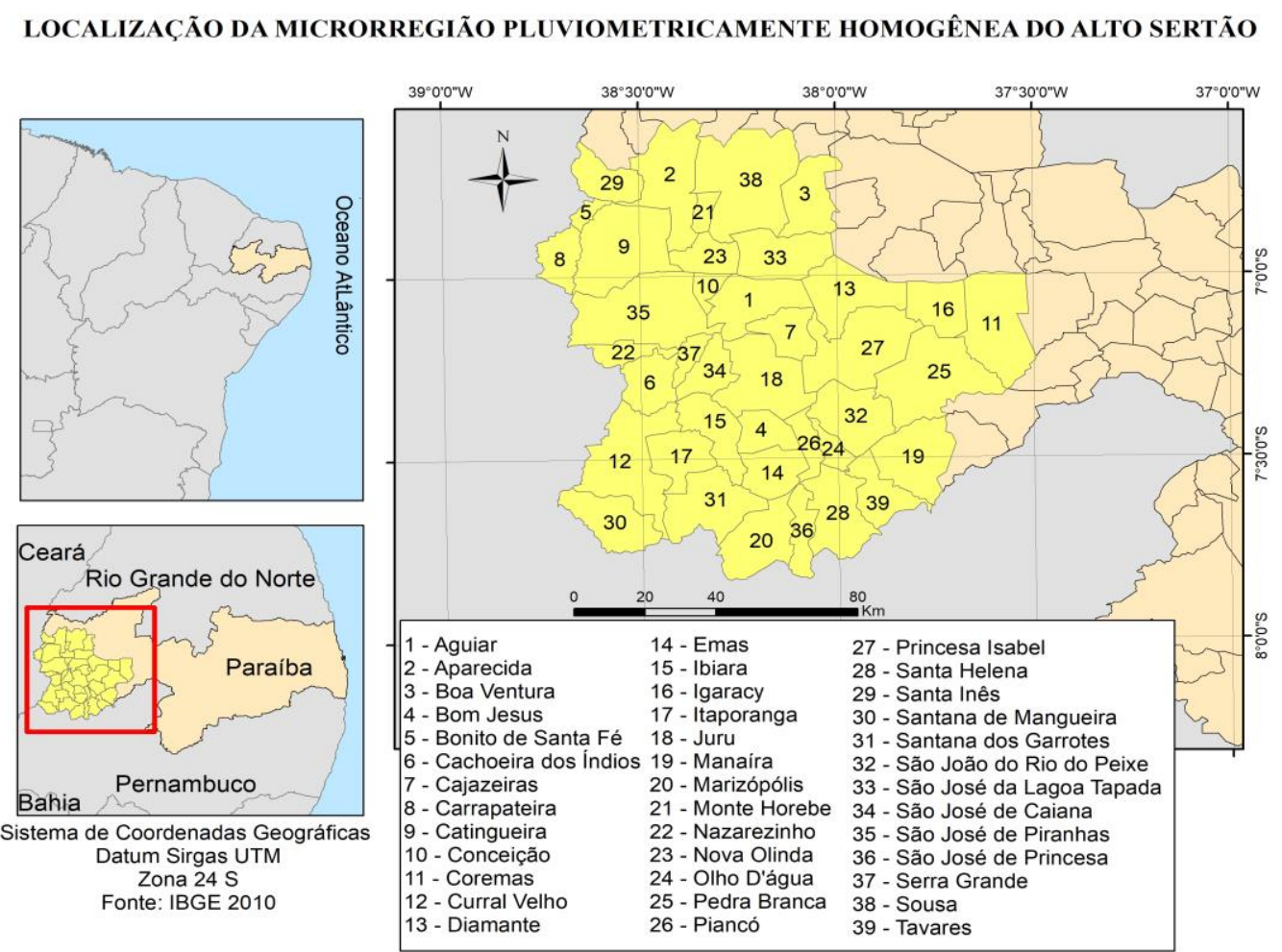

Figura 02: Localização da área de estudo. Elaboração: Diêgo Alan da Silva

No período de 2003 a 2016 foram reconhecidos 503 desastres climáticos na região do Alto Sertão paraibano. Desses, 493 foram reconhecidos por Situação de Emergência e 10 por Estado de Calamidade Pública.

Constatou-se que os decretos associados à estiagem ocorrem em maior número do que os desastres associados à seca. A Figura 03 apresenta a distribuição espaço-temporal dos municípios que decretaram SE por estiagem e seca na área de estudo, entre os anos de 2003 a 2016. 


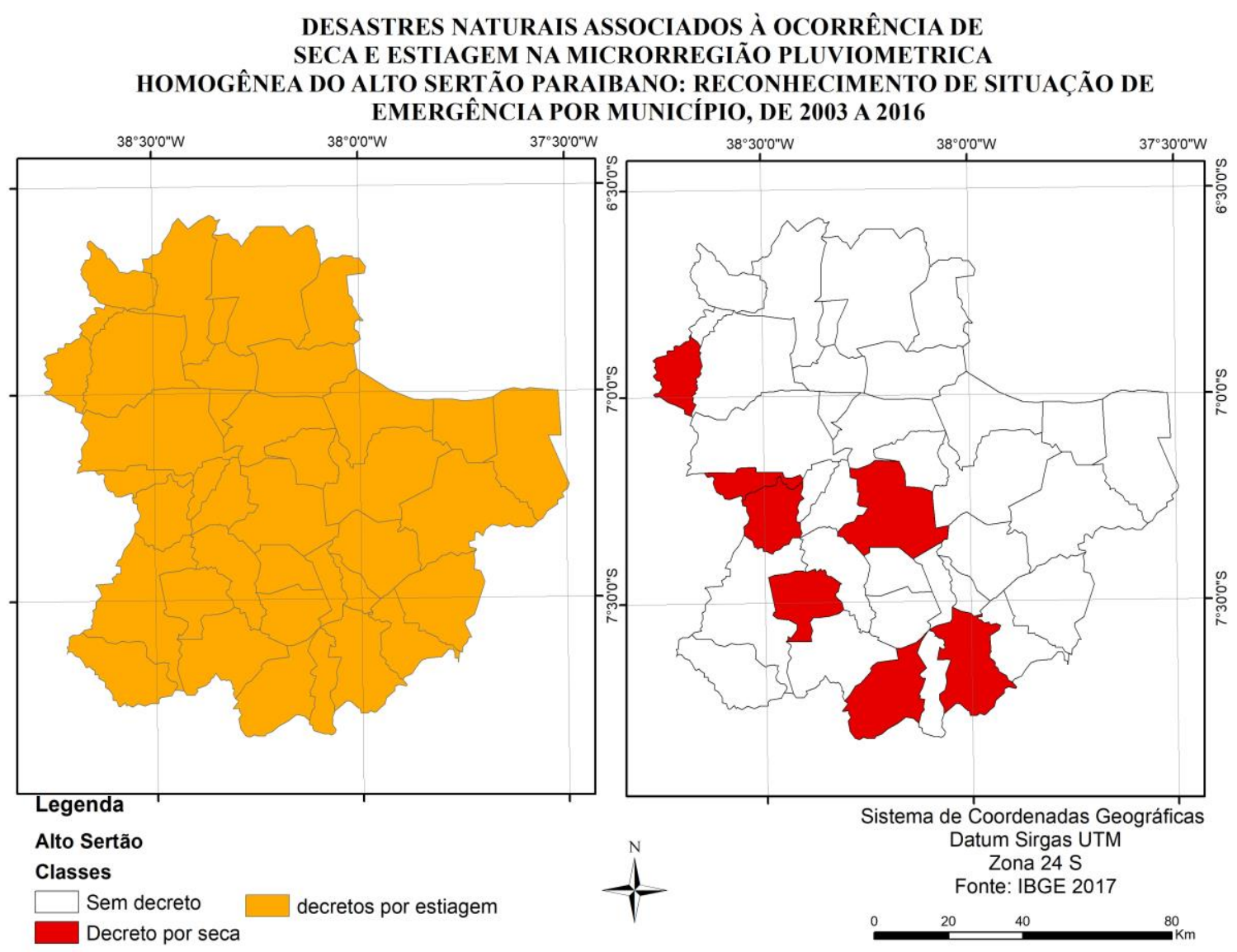

Figura 03: Distribuição espacial dos decretos por SE do tipo estiagem e seca entre os anos de 2003 a 2016, Alto Sertão da Paraíba. Fonte: BRASIL, 2016. Organização: Diêgo Alan da Silva

Todos os municípios da microrregião decretaram SE por estiagem, já para a seca foram sete municípios. A Figura 04 mostra o número anual de ocorrências de desastres de estiagem e seca decretados por SE, período 2003 a 2016. Observa-se que nos últimos cinco anos da série existe um aumento desses decretos para região.

No Figura 04 destaca-se o ano de 2013, ano de maior registro de desastres climáticos (117 ocorrências). Neste ano, todos os municípios do Alto Sertão decretaram SE por estiagem 3 vezes. Além disso, os registros de chuva ocorrem abaixo da média histórica, episódio que que ajuda esclarecer o montante de decretos por estiagem nesse ano. Nos anos subsequentes, todos os municípios da microrregião decretaram duas vezes, o que resultou em 78 reconhecimentos por ano. Já os anos que obtiveram apenas um decreto, a exemplo de 2003, teve uma precipitação acumulada próximo ou igual a média histórica (AESA, 2016; OLÍMPIO, 2016). 


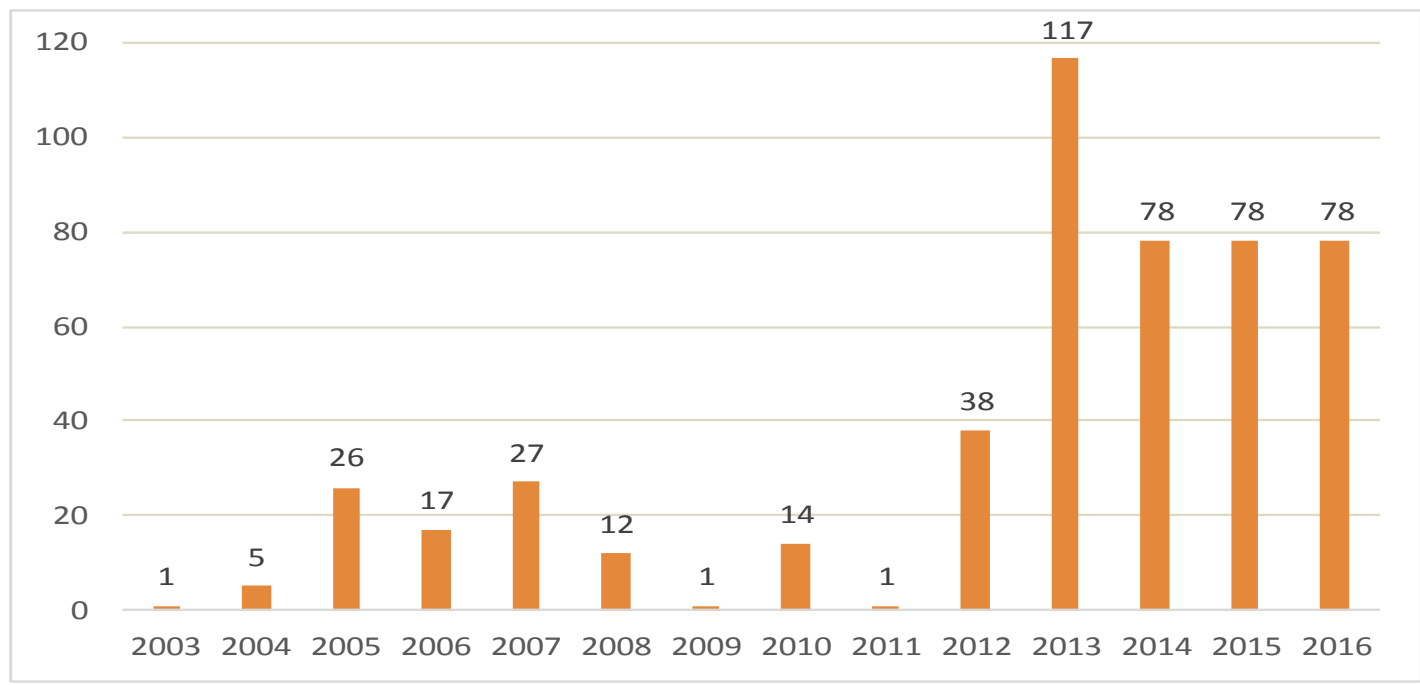

Figura 04. Gráfico com o número de decretos por SE do tipo estiagem e seca entre os anos de 2003 a 2016, Alto Sertão da Paraíba. Fonte: BRASIL, 2016. Organização: Diêgo Alan da Silva

Destaca-se que os reconhecimentos do tipo seca somente ocorreram nos anos de 2004 (três ocorrências) e de 2005 (cinco ocorrências). Cada município decretou apenas uma vez, a saber: Bonito de Santa Fé, Cachoeira dos Índios, Ibiara, Itaporanga, Manaíra, Monte Horebe, Princesa Isabel, e São José de Princesa. Os reconhecimentos por Seca correspondem a 1,6\% dos decretos por SE.

A Figura 05 mostra a distribuição espacial das recorrências de desastres deflagrados por estiagem que ensejaram decretos por SE nos municípios da região do Alto Sertão paraibano, 2003 a 2016.

O município que mais decretou SE por estiagem foi Manaíra, com 16 ocorrências. Os municípios de Igaracy, São João do Rio do Peixe, Nazarezinho e Princesa Isabel possuem 15 ocorrências cada; Aguiar, Curral Velho e Monte Horebe (14 ocorrências); Bonito de Santa Fé, Cachoeira dos Índios, Conceição, Juru, Santana dos Garrotes, Tavares, Nova Olinda e Santa Helena (13 ocorrências); Boa Ventura, Bom Jesus, Cajazeiras, Carrapateira, Coremas, Itaporanga, Santana de Mangueira (12 ocorrências). Por fim, o município que registrou o menor número de reconhecimentos foi Emas, com 9 ocorrências.

O número elevado de recorrências de desastres, denunciam que diante dos fenômenos de estiagem, os municípios apresentam baixo grau de resiliência, bem como serve para expor o grau elevado de vulnerabilidade socioambiental presente nos territórios dos municípios. 


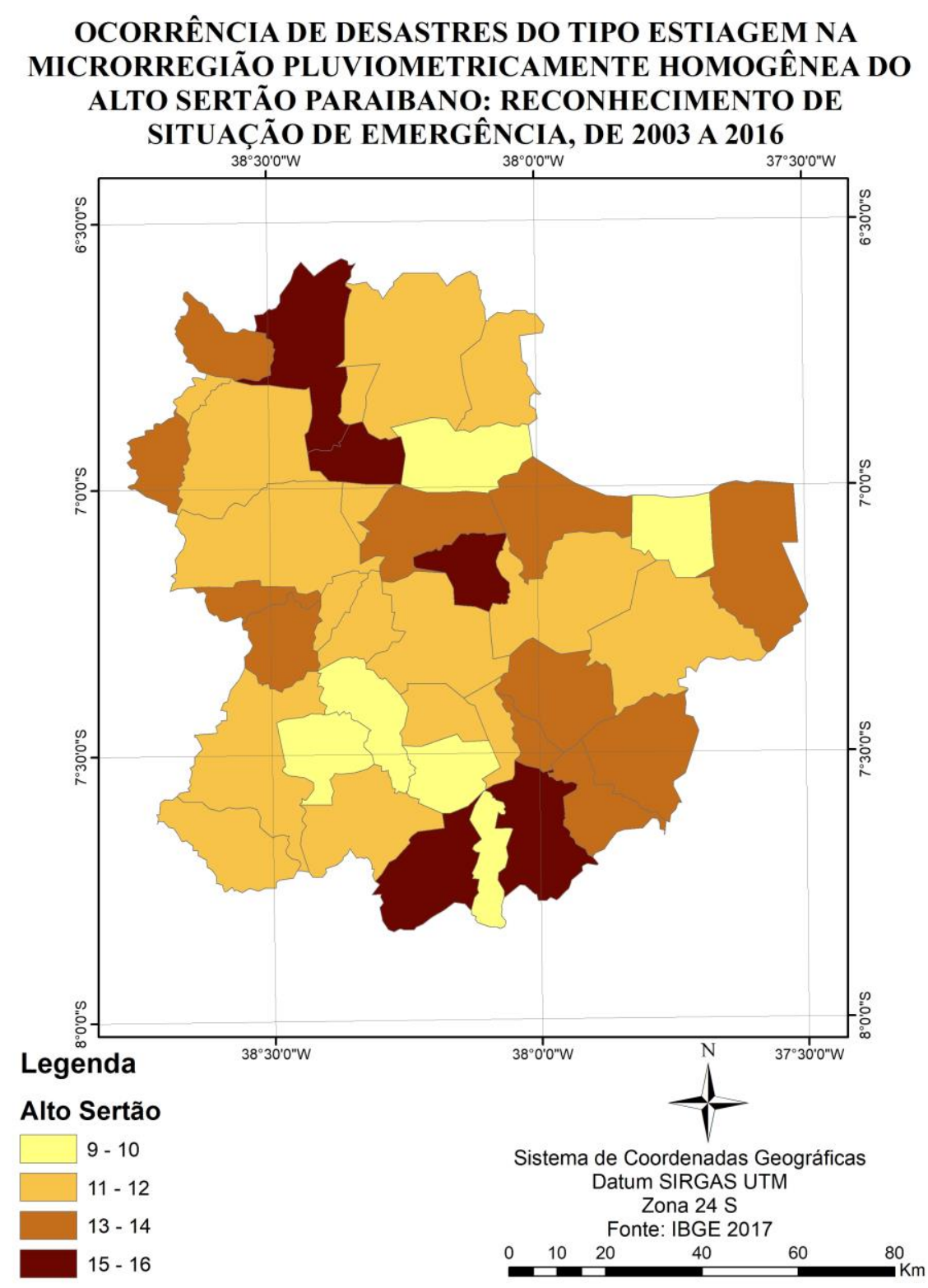

Figura 05: Distribuição espacial da frequência dos decretos por SE do tipo estiagem entre os anos de 2003 a 2016, Alto Sertão da Paraíba. Fonte: BRASIL, 2016. Organização: Diêgo Alan da Silva

A Figura 06 mostra a distribuição espacial das ocorrências de desastres deflagrados por estiagem que ensejaram decretos por ECP nos municípios da região do Alto Sertão paraibano, 2003 a 2016.

Cabe mencionar que entre os anos de 2003 e 2016, somente foram registrados decretos de Estado de Calamidade Pública para o fenômeno climático de estiagem. Os municípios que decretaram ECP foram: Aparecida, Bom Jesus, Diamante, Monte Horebe, Piancó, Santa Helena, São João do Rio do Peixe, São José de Caiana, São José de Piranhas e Serra Grande. Assim, foi contabilizado um total de 10 desastres de estiagem na região e todos ocorreram no ano de 2003. 


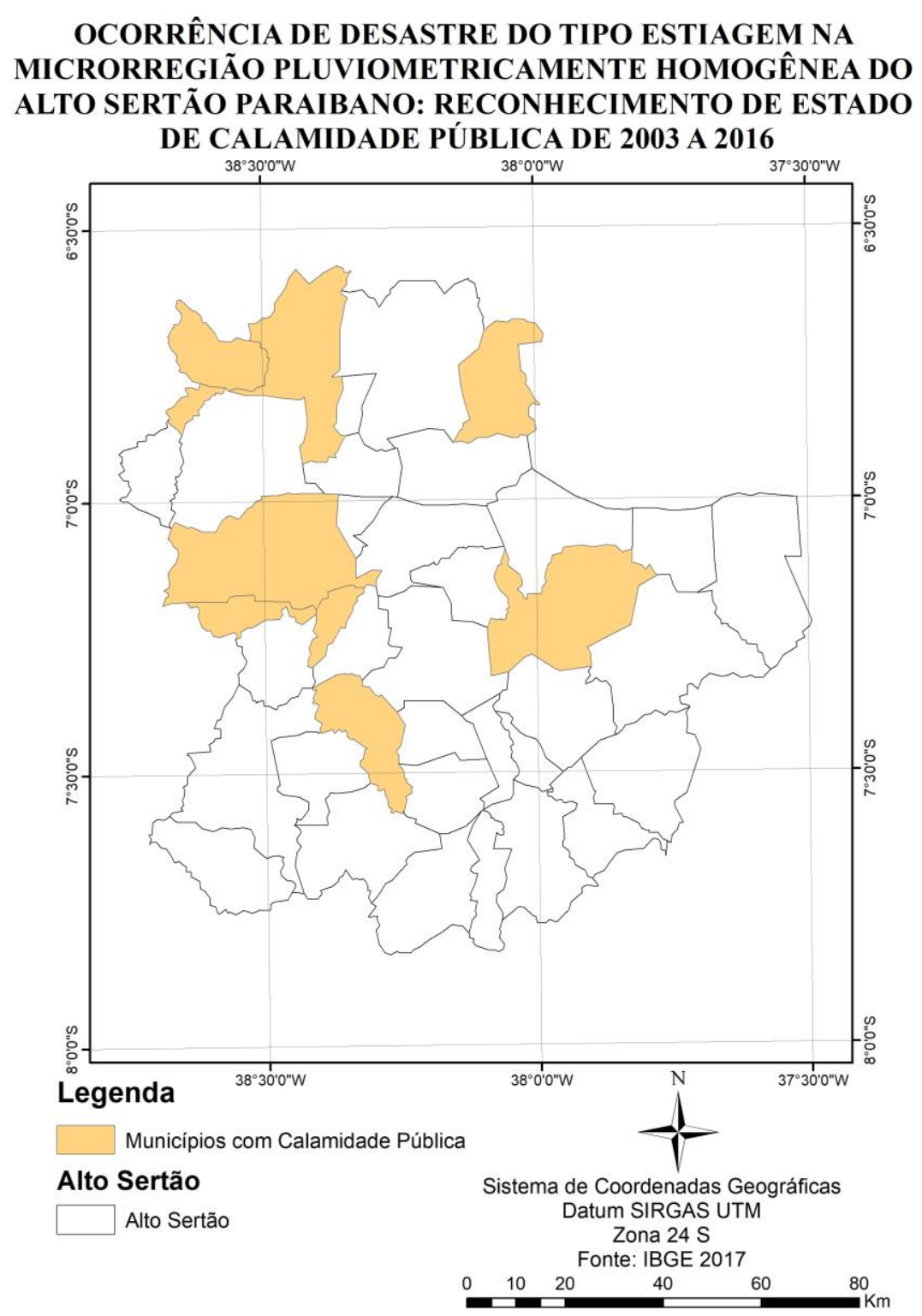

Figura 06: Distribuição espacial dos decretos por ECP do tipo estiagem entre os anos de 2003 a 2016, Alto Sertão da Paraíba. Fonte: BRASIL, 2016. Organização: Diêgo Alan da Silva

Moura et al (2016) identificaram que os reconhecimentos por decretos de ECP na região do Nordeste brasileiro são todos vinculados a desastres naturais de ordem climática (estiagem e seca) e hidrometeorológica (inundações graduais, enxurradas e chuvas intensas), exceto um reconhecimento de ECP vinculado a um desastre geológico (erosão marinha) registrado na cidade de Natal no ano de 2012.

Sobre a concentração de desastres por ECP no ano de 2003 Moura et al (2016) revelam uma importante informação que ajuda a esclarecer o motivo desse ano concentrar todos decretos de estiagem por ECP na área de estudo:

No que se refere ao Ranking dos reconhecimentos por ECP, a Paraíba ocupa a primeira posição quanto ao número de ocorrências (167 reconhecimentos). Esses reconhecimentos estão associados, predominantemente, a desastres climáticos (estiagem e seca). Cabe destacar que somente no ano de 2003 a Paraíba registrou 143 ocorrências de desastres reconhecidos por ECP, sendo 
141 reconhecimentos associados à estiagem e a seca e dois associados a desastres hidrometeorológicos. Tal gravidade pode ser ainda revelada se considerarmos que no Brasil foram reconhecidos 206 ocorrências de desastres por ECP no ano de 2003, ou seja, a Paraíba neste ano foi responsável por quase $70 \%$ das ocorrências no país. É também o estado brasileiro com maior número de ocorrências de desastres naturais reconhecidos por ECP entre os anos de 2003 a 2015. (MOURA et al, 2016, p. 264).

Sobre a informação levantada por Moura et al (2016), a qual foi também constatada na área de estudo, ainda não existe uma resposta clara sobre o fato da Paraíba concentrar o maior número de desastres decretados por ECP, em especial, para o ano de 2003. Acredita-se que o caminho a ser investigado deverá considerar a conjuntura política e administrativa do período em questão, além de informações que revelem o grau de vulnerabilidade socioambiental dos municípios paraibanos.

\section{CONSIDERAÇÕES FINAIS}

Foi contabilizado um total de 503 desastres climáticos sendo 493 por SE (485 por estiagem e 8 por seca) e 10 decretos por ECP (por estiagem) para a microrregião pluviometricamente homogênea do Alto Sertão Paraibano para o período de 2003 a 2016. Essa região possui 39 municípios e todos decretaram Situação de Emergência por estiagem. O ano de 2013 destaca-se por concentrar o maior número de decretos, também é destaque pois todos os municípios da região decretaram 3 vezes Situação de Emergência por estiagem neste ano.

A partir do ano de 2012 notou-se um considerável aumento dos desastres associados à estiagem em todos os municípios da área de estudo, e nos anos subsequentes foi identificado que os decretos continuaram em alta, episódio que evidencia o baixo grau de resiliência dos municípios frente a um dos maiores fenômenos de estiagem e seca já registrados no Nordeste brasileiro. Esse cenário mostra a importância de elaboração de estratégias para mitigar os efeitos dos desastres de natureza climática na região semiárida.

Por fim, os resultados apresentados neste trabalho precisam ser complementados com levantamentos que mostrem os prejuízos econômicos e os diferentes danos (humanos, materiais e ambientais) gerados pelos desastres de estiagem e seca na região do Alto Sertão da Paraíba. Somado a isso, também é relevante o desenvolvimento de estudos que apontem os diferentes graus de risco climático, risco social e de vulnerabilidade socioambiental nos municípios que integram a região.

\section{REFERÊNCIAS}

AESA. Agência Executiva de Gestão de Águas. Disponível em: <http://www.aesa.pb.gov.br/aesawebsite/>. Acesso em: 06 nov. 2017. 
ALVES, J. M. B. Aspectos climatológicos do Nordeste brasileiro com ênfase a região semiárida: principais causas da variedade pluviométrica. In: Anais do $1^{\circ}$ Simpósio sobre Captação de Água de chuva no semiárido Brasileiro. Petrolina, PE, 17 - 21 de novembro de 1997. CD ROM.

AZEVEDO, P. V., SILVA, V. P. R. Índice de seca de Bhalme \& Mooley: uma adaptação regional. In: CONGRESSO BRASILEIRO DE METEOROLOGIA, 8., 1994, Belo Horizonte. Anais... Belo Horizonte: SBMET, 1994. Vol. 2. p.696-699.

BRASIL, Ministério da Integração Nacional. Instrução Normativa no 01, de 24 de Agosto de 2012 do Ministério da Integração Nacional, 2012. Disponível em: <http://www.mi.gov.br/documents/10157/3776390/Instru_Normativa_01.pdf/8634a6e3-78cc-422aaa1d-7312ce7f1055>. Acesso em: 20 set. 2016

BRASIL. Ministério da Integração Nacional. Secretaria Nacional de Proteção e Defesa Civil. Situação de emergência e estado de calamidade pública: reconhecimentos realizados, 2016. Disponível em: <http://www.mi.gov.br/reconhecimentos-realizados>Acesso em: 6 mar. 2016.

EMBRAPA, Centro Nacional de Pesquisa de Solos (Rio de Janeiro, RJ). Sistema Brasileiro de classificação de solos . Brasília: SPI, 1999. 412p.

FERREIRA, A. G; MELLO, N.G.S. Principais sistemas atmosféricos atuantes sobre a região Nordeste do Brasil e a influência dos oceanos Pacífico e Atlântico no clima da região. Revista Brasileira de Climatologia, vol.1, nº 1. p.15-28, 2005.

IBGE. Instituto Brasileiro de Geografia e Estatística. Cidades. Disponível em: <https://cidades.ibge.gov.br/xtras/uf.php?lang=\&coduf=25\&search=paraiba>. Acesso em: 17 nov. 2016.

MOREIRA, E. R. Estruturação do território municipal paraibano: na busca das origens. Cadernos do LOGEPA, v. 2, n. 2, 2010.

MOURA, M. O; CUNICO, C; TEMOTEO, K. K. S; SILVA, N. T. Desastre natural associado à ocorrência de chuva extrema na cidade de Patos, Paraíba. In: Paraíba: pluralidade e representações geográficas, v.2, SILVA, A. B, GUTIERRES, H. E. P, GALVÃO, J. C. (Org.). Campina Grande: EDUFCG, 2017.

MOURA, M. O; CUNICO, C; NÓBREGA, R. S; DUARTE, C. C. Desastres hidrometeorológicos na região Nordeste do Brasil: distribuição espaço-temporal dos reconhecimentos de Estado de Calamidade Pública. Caderno de Geografia, Belo Horizonte, v. 26, n. 2, p. 259-271. 2016. Disponível em: $\quad$ http://periodicos.pucminas.br/index.php/geografia/article/view/p.23182962.2016v26nesp2p259>. Acesso em: 11 nov. 2017.

OLÍMPIO, J. L. S Analise multicritério dos desastres naturais: um estudo sobre a seca na região nordeste do Brasil. 2017. 238f. Tese (Doutorado) - Programa de Pós-Graduação em Geografia, Universidade federal do Ceará, Fortaleza, 2017.

SILVA, L. L. Precipitações Pluviais de Pré-Estação Chuvosa no Período Chuvoso e suas Influências na Produtividade Agrícola da Paraíba. Dissertação (mestrado). Campina Grande: Programa de Pós-Graduação em Meteorologia/UFCG, 2007. 114p.

UNISDR, Terminology on Disaster Risk Reduction. United Nations Office for Disaster Risk Reduction - UNISDR. Geneva: United Nations, 2009, 30p. Disponível em: 
http://www.preventionweb.net/files/7817_UNISDRTerminologyEnglish.pdf. Acesso em: 07 nov. 2017.

Recebido em: 23/04/2018

Aceito para publicação em: 04/05/2018 